\title{
Cognitive relations in online learning: Change of cognitive presence and participation in online discussions based on cognitive style
}

\author{
Sezan Sezgin* \\ Faculty of Education, Mehmet Akif Ersoy University, Burdur, Turkey
}

ORCID: 0000-0002-0878-591X

\begin{tabular}{|c|c|}
\hline Article history & This study aims at investigating the change of cognitive presence \\
\hline $\begin{array}{l}\text { Received: } \\
05.07 .2020\end{array}$ & $\begin{array}{l}\text { (CP), which is one of the basic variables for effective learning in } \\
\text { online discussions, based on the cognitive style. Cognitive styles of }\end{array}$ \\
\hline $\begin{array}{l}\text { Received in revised form: } \\
19.09 .2020\end{array}$ & $\begin{array}{l}\text { the participants were identified based on the group embedded } \\
\text { figures test (GEFT). The participants of the study took part in online } \\
\text { discussions for seven weeks. Content analysis was used to measure }\end{array}$ \\
\hline $\begin{array}{l}\text { Accepted: } \\
20.09 .2020\end{array}$ & $\begin{array}{l}\text { cognitive presence in students' online discussions. The analysis } \\
\text { was based on practical inquiry (PI) model which defines four }\end{array}$ \\
\hline Key words: & phases of cognitive presence. The data were also analysed using the \\
\hline $\begin{array}{l}\text { Ccognitive presence, } \\
\text { cognitive style, } \\
\text { field dependence, } \\
\text { online discussions, } \\
\text { higher-level online learning, } \\
\text { online participation }\end{array}$ & $\begin{array}{l}\text { nonparametric tests, Spearman Rhu correlation, and descriptive } \\
\text { statistics. The findings indicate that, in regard to the cognitive } \\
\text { presence of the participants, those phases with the highest } \\
\text { frequency are found to be exploration and triggering event. It is also } \\
\text { found that the CPs of the participants do not vary based on their } \\
\text { cognitive styles. In addition, unlike what was reported by previous } \\
\text { studies there are no significant differences between the number of } \\
\text { words used by the participants and the rate of involvement in online } \\
\text { discussions depending on their CPs. On the other hand, there are } \\
\text { moderate and strong correlations between the participants' CP } \\
\text { phases suggesting that the CP phases may be developed in relation } \\
\text { to one another. Based on the findings, some suggestions are } \\
\text { developed in regard to the scope of learning analytics and } \\
\text { discussion dynamics concerning the discussion environments in } \\
\text { online learning. }\end{array}$ \\
\hline
\end{tabular}

\section{Background}

Online discussions are among the information exchange acts which are frequently employed in social media or educational activities. Such acts are often used to facilitate the online learning experience, especially in online and blended learning environments. With the increase of various online programs, massive open online courses, and blended learning approaches, online discussion environments have become the most important spaces for online learning in the context of the production and sharing of collective knowledge. The social interaction and argumentation process between learners and experts in asynchronous or synchronous online environments are also an important social knowledge construction process (Du \& Wagner, 2007). It can be argued that in future,

\footnotetext{
*Correspondency: sezansezgin@mehmetakif.edu.tr
} 
such processes may also include teaching and guidance agents developed through artificial intelligence.

Online discussions are, actually processes in online environments that maintain the features of group interaction and learning community in face-to-face learning settings. However, due to the nature of online learning social autonomy that is perceived and reflected by individuals in online education makes the structure of discussions different from those in face-to-face education. It can be said that online discussions are largely freer. From this point of view, it is important to determine how online discussions will be conducted by a moderator/manager. Therefore, the triggering component in online discussions are significant in terms of the quality of discussions. The nature and continuity of the discussions directly affect learning. The reason for this situation is that online discussions have the potential to improve learners' higher-order thinking (Darabi, Arrastia, Nelson, Cornille, \& Liang, 2011). Garrison, Anderson, \& Archer (1999) argue that online discussions require participants to make use of cognitive collaborations such as integration, synthesis, and evaluation of ideas, thereby creating a high-level thinking potential. This collective act of the participants indicate that they learn something from one another and construct meaning and knowledge which clearly suggest that social context affects the cognitive development of learners.

It is thought that in online discussions, a collective process supported by the higher-level question prompts improve learners' cognitive contributions and involvement (DeNoyelles, Zydney, \& Chen, 2014, Ertmer, Sadaf, \& Ertmer, 2011). This support is generally realized through the use of well-established discussion questions. These questions should be employed together with well-organized teaching strategies. Both effective teaching strategies and open-ended online discussion questions that may engage learning in the process may trigger the cognitive mechanisms of learners. Such a learning environment may produce long-lasting learning. All these topics are about the effects of online discussion activities on online learning and how to employ online discussion for educational purposes. However, although online discussions are extremely desired platforms for learners, it should not be forgotten that involvement in online discussions may be affected by distinct factors. Such factors may also have impact on the quality of online learning. Thereupon, it is possible to argue the following: "If we are talking about collective and utilitarian knowledge building in online learning, we should encourage every learner to participate in online discussions and also, identify the reasons or individual characteristics that keep them away from discussions. In this way, by adjusting the type of online discussions, we can improve learner participation and therefore impact on learning."

This study focuses on cognitive characteristics of learners in regard to their involvement in online discussions. Some of these cognitive characteristics include cognitive style (Witkin, Moore, Goodenough, \& Cox, 1977), metacognition \& monitoring (Flavell, 1979) and critical thinking (Kovanović et al., 2016). Such variables, as self-directed information processing attributes (Zimmerman, 2002), are thought to have "a substantial effect on students' participation in online discussions in a deep and meaningful way" (Kovanović et al., 2016). On the other hand, one of the theoretical frameworks that best describes participation in online discussions and learning groups is Community of Inquiry (CoI). CoI describes the knowledge construction process which requires the presence of stakeholders in an online environment (learners and instructors) and which is based on social interactions. The goal of this process is the higher-level learning and thusly, 
predicts learners' online learning experiences (Kovanović et al., 2016). In the current study the cognitive presence that is the cognitive dimension of this framework is analysed.

\section{CoI Framework and Cognitive Presence of Learners}

CoI framework (Garrison, Anderson, \& Archer, 2001) argues that in-depth and significant learning in online learning settings (Akyol \& Garrison, 2011) depends on the development of a community of inquiry. In other words, the CoI framework accounts for the distinct components of social learning among the online learning groups (Shea, 2006). The goal is to reduce or eliminate the problems that may arise due to the lack of interaction in online learning environments to produce successful online learning. CoI essentially points out that online learning can be permanent if knowledge construction takes place collectively and on the condition that it is based on critical thinking.

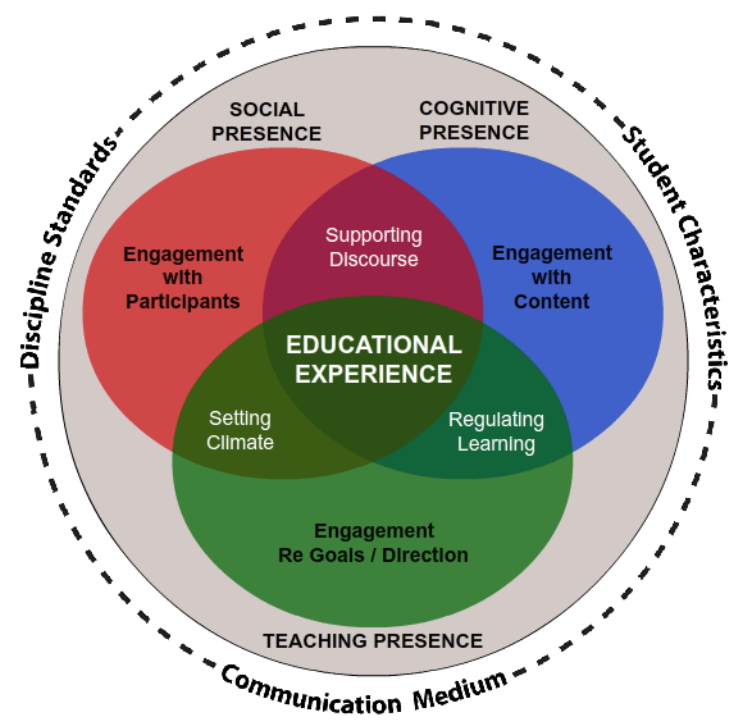

Figure 1. Community of Inquiry Theoretical Framework (Garrison \& Akyol, 2015)

There are three different elements of permanent, efficient, and assimilated online learning that can also be described as successful online learning: Social presence (SP), teaching presence (TP), and cognitive presence (CP) (Figure 1). Social presence refers to the level of social and affective interaction of learners in online learning group (Arbaugh, Bangert, \& Cleveland-Innes, 2010) and the learning climate (Akyol \& Garrison, 2011), whereas teaching presence refers to the management of the course delivered in the teaching process (Shea et al., 2012). In the study the focus is on the cognitive presence which is one of the CoI components.

\section{Cognitive Presence $(C P)$}

Garrison, et al. (2001) argue that the CP is the basic component that defines the CoI model which they described it as "the extent to which learners are able to construct and confirm meaning through sustained reflection and discourse". It is reported that the $\mathrm{CP}$ is the hardest presence construct which can be improved in online environments (Garrison \& Arbaugh, 2007; Garrison \& Cleveland-Innes, 2005), but once improved, it significantly contributes to provide higher levels of learning for online environments (Rourke \& Kanuka, 2009). For many researchers, CP is a cognitive mediator to reach and explore deep cognitive thinking in learning (Akyol \& Garrison, 2011). The CP is based 
on the practical inquiry model which accounts for the knowledge-building process in the online educational groups (Kovanović et al., 2016). Put differently, the CP is the "multivariate measure of critical and creative thinking" (Shea et al., 2012) to develop a solution to the problems during the online discussions (Akyol \& Garrison, 2011). The PI model (Schrire, 2004) is made up of four phases which describes the knowledge-building process in the cognitive dimension of online educational discussions (Garrison \& Anderson, 2003; Kovanović et al., 2016; Sadaf \& Olesova, 2017).

The first phase is triggering event. It refers to the understanding of the problem at the beginning of the inquiry process. Exploration is the second phase in which related information is searched for, and an explanation is developed and suggested (Wang \& Chen, 2008). The third phase is integration. This phase is the construction of a structured solution to the problem, in other words, a decision is made by integrating various ideas about the solution (Wang \& Chen, 2008). The fourth and last phase is resolution. At this phase the solution of the problem is placed in a meaningful framework and a specific solution is resorted to with a view to solving it (Wang \& Chen, 2008). Of them, the phases of triggering and exploration indicate lower levels of cognitive presence, whereas the integration and resolution phases represent high levels of cognitive presence (Sadaf \& Olesova, 2017).

Supporting the cognitive presence in online learning environments is necessary and significant for effective learning settings (Garrison et al., 2001). Thereupon, high levels of cognitive presence is possible only when individual variety exists in online learning settings. In the same line, Lee \& Lee (2006) reported that in the online discussion groups with participants whose individual characteristics significantly vary metacognitive interaction occurs at higher levels. Similarly, Moore and Marra (2005) argue that group composition is much more significant than other factors to improve cognitive presence.

One of the personal characteristics that deals with the autonomy and characteristics of learners is cognitive style. Cognitive style that is one of the uniform personal characteristics has not been sufficiently analysed in the literature in relation to individual differences in learning. Cognitive style is the way that individuals choose to organize and arrange information (Messick, 1984). This way specifies the approaches that individuals choose in information processing processes such as the way of approaching towards, gathering, analysing, evaluating, and interpreting the information (Sternberg \& Zhang, 2005). Individuals are categorized into two groups based on their cognitive styles: field dependent and field independent.

\section{Field Independence and Field Dependence}

The classification of individuals as field independent and field dependent developed by Witkin, Oltman, Raskin, and Karp (1971) assumes that individuals vary based on their traditional behaviour patterns and perception structures when they come across an event, problem or situation. Field dependent individuals have a global perceptual pattern and see parts of the situation or problem they need to perceive but cannot combine these parts together (Davis, 1991; Richardson \& Turner, 2000). Field independent individuals, on the other hand, see a situation or a problem presented to them as a whole. However, they can also recognize and analyse the elements of these structures. Further characteristics of field independent and field dependent individuals are given in 
Table 1 (Davis, 1991; Riding \& Cheema, 1991; Richardson \& Turner, 2000; Saracho, 1997).

Table 1. Personality traits of the field dependent and field independent individuals (adapted from Saracho, 1997)

\begin{tabular}{|c|c|}
\hline Field-dependent (FD) individuals & Field-independent (FI) individuals \\
\hline Holistic & Analytical \\
\hline $\begin{array}{l}\text { It takes long time for them to solve the } \\
\text { problems of the same type. }\end{array}$ & $\begin{array}{l}\text { They solve the different types of problems by } \\
\text { structuring them }\end{array}$ \\
\hline $\begin{array}{l}\text { They have developed social skills and mostly } \\
\text { adapt to social environments. }\end{array}$ & $\begin{array}{l}\text { They have less developed social skills and are } \\
\text { mostly independent from the society. }\end{array}$ \\
\hline They can accept a system as it is. & They can find defects in a system. \\
\hline $\begin{array}{l}\text { They need more interaction with instructors or } \\
\text { peers. }\end{array}$ & $\begin{array}{l}\text { They do not need more interaction with instructors } \\
\text { or peers. }\end{array}$ \\
\hline $\begin{array}{l}\text { They need external resources to identify } \\
\text { themselves. }\end{array}$ & They depend on their internal values and standards. \\
\hline $\begin{array}{l}\text { They care about human relationships and want } \\
\text { people to be around them. }\end{array}$ & They do not bother being socially isolated. \\
\hline $\begin{array}{l}\text { They succeed in jobs that require verbal } \\
\text { communication skills such as teaching and } \\
\text { marketing, etc. }\end{array}$ & $\begin{array}{l}\text { They succeed in jobs that require numerical skills } \\
\text { such as physics and math. }\end{array}$ \\
\hline They can learn better studying in groups. & They can learn better studying individually. \\
\hline
\end{tabular}

As can be seen in Table 1 the FI and FD individuals have totally different characteristics that may also be observed in online learning environments. However, it should be noted that neither of these characteristics make some individuals much more superior than the others. Cognitive styles are not related to intelligence but guide the choices of individuals. Given that personal traits of individuals have a significant impact on their learning, the distinction between field independent and field dependent may be useful in developing effective teaching and learning environments.

There are two theoretical strengths relevant to this study. One of them is Community of Inquiry (CoI) framework which provides guidance about dynamics of successful online and blended learning environments. The other one is a constant individual difference, cognitive style, that provides an explanation about the data processing phases of individuals. This study attempts to analyse the learners' cognitive presence in online discussions based on their cognitive styles. In line with this aim the study tries to answer the following research questions:

- Is there a pattern of groups' overall cognitive presence from Week 1 to Week 7 of the online argumentation process?

- Is there any change in the level of participation and the number of words used by the participants in relation to the weeks or to their cognitive styles?

- Is there a pattern of cognitive style groups' cognitive presence from Week 1 to Week 7 of the course?

- Is there a significant correlation between CP phases and CS groups?

\section{Methodology}

This study is an example of associational research seek to observe relationships between different variables (Fraenkel, Wallen, \& Hyun, 2012). Nonparametric tests, Spearman Rhu correlation, and descriptive statistics were used to explain the associations. 


\section{Participants and Measures}

The participants of the study are 73 pre-service teachers. However, eleven of these individuals were not participants in online discussions. In addition, five individuals took part in only one discussion session, but their messages were not eligible and did not contain any indication of cognitive presence. Therefore, the data from these participants were not used in the analysis. As a result, the data from 57 pre-service teachers were included in the study. In online discussions there were $28 \mathrm{FI}$ (10 female and 18 male) and 29 FD (10 female 19 male) participants. The cognitive style of the participants was identified through the Group Embedded Figures Test (GEFT) which was developed by Witkin et al. (1971). The cognitive presence of the participants was identified with the practical inquiry model and coding indicators (Garrison, et al., 2001).

\section{Group Embedded Figure Test (GEFT):}

The GEFT is a well-known cognitive diagnosis instrument which was designed to measure individuals' degree of field independency. This test depends on tracing the simple figure embedded within a larger complex figure. The respondents are required to find and make clear the simple geometric figure with pencil within the time specified for each item. The GEFT has a proper reliability since its Spearman-Brown coefficient was reported to be 0.82 . The test consists of three sections with 25 items, herein, the first section contains seven items for practice. Accordingly, the main test consists of 18 testing tasks, so the possible maximum score is 18 .

\section{Examining cognitive presence via thematic analysis based on Practical Inquiry (PI) model}

Thematic analysis based on "Practical inquiry (PI) model" and its coding indicators (Garrison, et al., 2001) was used in this study to measure cognitive presence in learner online discussions. As indicated before, the practical inquiry (PI) model includes four phases (Table 2) in describing cognitive presence in online learning (Garrison \& Anderson, 2003). Research confirmed that thematic analysis via PI model is an accepted and reliable way of assessing cognitive presence in online discussions (Akyol \& Garrison, 2011; Schrire, 2006). In the thematic analysis the messages by the participants were analysed based on the indicators given in Table 2 to identify which cognitive presence phase the messages were in. The unit of the thematic analysis is a "meaning unit" by the participants, not a single message. Each number of arguments, the categories in cognitive presence for each cognitive group was converted to a percentage to compare the results between the groups.

Table 2. Practical inquiry model and coding indicators (Akyol \& Garrison, 2011)

\begin{tabular}{lll}
\hline Phase & Descriptor & Indicator \\
\hline Triggering event & Evocative (inductive) & Recognize problem \\
& & Puzzlement \\
Exploration & Inquisitive (divergent) & Divergence \\
& & Information exchange \\
& & Suggestions \\
& & Brainstorming \\
Integration & Tentative (convergent) & Intuitive leaps \\
& & Convergence \\
Resolution & & Synthesis \\
& Committed (deductive) & Solutions \\
& & Apply \\
\hline
\end{tabular}




\section{Research Process and Analysis}

The study was conducted at the faculty of educational sciences of a state university during the fall semester of 2019-2020 academic year. The courses "Designing Multimedia Environments" and "Distance Education" which are officially delivered in a face-to-face manner were delivered in a blended manner for seven weeks. During the semester, an online discussion activity based on the seven discussion prompts was created by the course instructor on various topics about online education approaches, instructional design and also, technology. The reason for the creation of this activity was to test the pre-service teachers' knowledge about different learning-teaching approaches and technological issues, and to develop different ideas, practices, methods, and perspectives on these subjects.

In the study the data on the cognitive style of the participants were collected through the GEFT. It was administered to the participants in the groups of ten. Each session took for twenty-five minutes, including introduction and instructions. The data obtained were analysed using the evaluation framework developed by Witkin et al. (1971). The minimum score from the GEFT is 0 , whereas the maximum score is 18 . Those having higher scores are categorized as the FI individuals. However, the range to differentiate the FI and FD individuals is not clearly given by Witkin et. al. (1971). In some studies, this range is identified based on the formula $\bar{x}+1 / 2 \mathrm{SD}$ using the standard deviation of the group and the means (Chang, Chen, \& Jhan, 2015; Mutlu \& Temiz, 2011). Accordingly, in this study, those with total GEFT score greater than $(\overline{\mathrm{x}}+1 / 2 \mathrm{SD})$ were accepted as FI, and those lesser than ( $\overline{\mathrm{x}}-1 / 2 \mathrm{SD})$ were categorized as FD.

Thematic analysis of asynchronous online discussions was used as another data source in this study. In the analysis process, participants' cognitive presence was explored by analysing the seven weeks of discussions via PI model. Before the analysis, an expert on teaching design was trained on the PI model and its indicators. In training, sample messages were used in a two-step pilot study. All the student postings were archived before the actual coding process started. The thematic analysis was carried out using the NVivo 12 software. The participants were grouped as FI or FD based on their GEFT scores and the messages (codes) were classified based on the phases of cognitive presence. Some of the longer messages with more than one argument were classified into different phases. In order to establish coder reliability, the messages were analysed twice in one-month interval. The intra-rater reliability coefficient was found to be .92 . Those messages which were evaluated different in the first and second analyses were reanalysed which produced $100 \%$ consistency. A similar process was used in identifying the intrarater coefficient. Following the analyses independent coders discussed the inconsistently categorized messages and reached consensus. The final interrater reliability coefficient was found to be .87 and the analyses of messages were repeated until $100 \%$ agreement was reached.

\section{Results}

\section{Is there a pattern of groups' overall cognitive presence from Week 1 to Week 7 of the online argumentation process?}

As a result of seven-week online discussions 250 messages and 1212 statements were posted. The results of the thematic analysis showed that the most frequent type of messages is that of exploration (50,57\%). It is followed by the triggering event $(31,25 \%)$. 
The other types, namely integration $(14,77 \%)$ and resolution $(3,41 \%)$, are found not to be used frequently by the participants.

Table 3. Overall cognitive presence from Week 1 to Week 7 of the online argumentation process

\begin{tabular}{|c|c|c|c|c|c|c|c|c|}
\hline $\begin{array}{l}\text { Time } \\
\text { Span }\end{array}$ & $\begin{array}{c}\text { Triggering event } \\
\text { (n) }\end{array}$ & $\overline{\mathbf{x}}(\%)$ & $\begin{array}{c}\text { Exploration } \\
\text { (n) }\end{array}$ & $\overline{\mathbf{x}}(\%)$ & $\underset{(n)}{\text { Integration }}$ & $\overline{\mathbf{x}}(\%)$ & $\begin{array}{c}\text { Resolution } \\
\text { (n) }\end{array}$ & $\begin{array}{c}\overline{\mathbf{x}} \\
(\%)\end{array}$ \\
\hline $\begin{array}{l}\text { Week } \\
1-2\end{array}$ & 49 & 13,92 & 81,00 & 23,01 & 26,00 & 7,39 & 4,00 & 1,14 \\
\hline $\begin{array}{l}\text { Week } \\
3-5\end{array}$ & 26 & 7,39 & 44,00 & 12,50 & 15,00 & 4,26 & 6,00 & 1,70 \\
\hline $\begin{array}{l}\text { Week } \\
6-7\end{array}$ & 35 & 9,94 & 53,00 & 15,06 & 11,00 & 3,13 & 2,00 & 0,57 \\
\hline Total & 110 & 31,25 & 178,00 & 50,57 & 52,00 & 14,77 & 12,00 & 3,41 \\
\hline
\end{tabular}

Table 3 presents the participants' total level of cognitive phase by weeks. The process of seven-week online discussion is analysed under three headings. The low and moderate level components of cognitive presence $(\mathrm{CP})$, namely triggering event and exploration, are found to be at the highest level during the early weeks and to decrease between the weeks of three and five. During the last two weeks these are found to increase again. Another CP integration, may be counted as high-level CP phase, is at the highest level in the first two weeks. Then, it decreased over the remaining weeks. The top-level CP phase, resolution, reached the peak level between the weeks 3-5. Even though these numbers show variation, they do not represent statistical differences. The proportions of CP levels in each of the seven-week course were analysed using the Kruskal-Wallis test. The analysis showed that the statistically significant difference occurs only in the exploration phase of the cognitive presence during the seven-week course, $\chi 2(2)=7,909, p<.05$. Post hoc pairwise comparisons using The Bonferroni correction, $\mathrm{p}=.016$ found only one significant pairwise comparison, that is, between the weeks 1-2 and the weeks 3-5. During these periods the exploration phase significantly decreased.

\section{Discussion:}

It is an expected result that the phases of CP may vary among the participants. Research indicates that the most frequent cognitive presence pattern is the exploration phase in online discussions, but learners cannot manage to switch to the other phases of the cognitive presence, namely the phases of integration and resolution (Garrison, et al., 2001; Kanuka, Rourke, \& Laflamme, 2007; Koh, Herring, \& Hew, 2010; Kovanović, Gašević, Joksimović, Hatala, \& Adesope, 2015; Morueta, López, Gómez, \& Harris, 2016; Wang \& Chen, 2008). This result may be explained with understanding the specific characteristics of each phase of the $\mathrm{CP}$.

The exploration phase reflects the cognitive processes that involve an "explanation" and "exploration" from the learners' own perspective. At this phase, discovery and solution attempts take place in different directions which learners realize through researching the discussion content of online discussion. Also, learners may develop novice hypotheses. It is in fact a brain storming process and its processing is a phase of socially constructing knowledge. Learners discover new information and then, construct it. During this process they may affect the views of one another. As the debate progresses, the views become much deeper instead of being very simple, and it is one of the characteristics of exploration phase (Garrison et al., 2001). It is not surprising that this phase is much more frequent than the others due to these features, in other words, such characteristics may 
lead to this phase to be the most frequent $\mathrm{CP}$ phase in the study. In addition, during the online discussions the use of innovative research topics might make this phase much more evident which is a phase of brainstorming and discovery. On the other hand, similar to the views of Garrison et al. (2001), it should be added that democratic environment of the social media in which online discussions were carried out may make this phase much more evident. As the debate progresses, the views switch from basic level to deeper level in the exploration phase which may account for the decrease of this phase over time.

The second frequent $\mathrm{CP}$ phase is found to be the phase of triggering event $(31,25 \%)$. In the studies dealing with the cognitive presence in online learning environments, this phase is not reported as one of the most frequent phases. The reason for the current finding can be attributed to the content of the questions used in the online discussions. Garrison et al. (2001), stated that framing the discussion topic adequately by online educators may decrease the triggering event rate. This would seem to be reasonable since in the current study the content of the discussion topics was not totally structured and framed by the educators. Instead, the content was about blurred innovative approaches in teacher training. Therefore, during the triggering phase learners frequently employed the "clarifying the task" and the task of "re-expressing the topic".

The remaining arguments of the learners belong to the integration phase $(14,77 \%)$ and the resolution phase $(3,41 \%)$. This finding is consistent with the previous findings. At the integration phase a kind of knowledge synthesis occurs. Whence, it is a demanding cognitive process which requires a certain period of time to develop arguments. At this phase learners discuss their views, take part in an active interaction with each other and integrate different perspectives into their solution processes. To that end, the integration phase can also be described as a process of social construction and solution development. However, the solutions suggested at this phase may also cause learners to be more careful considering the social environment. As indicated in Wang \& Chen (2008); "as the integration phase progressed, shared cognition emerged" (Wang \& Chen, 2008). All these refer to a time-consuming process. In the study by Akyol \& Garrison (2011) it is found that the most frequent $\mathrm{CP}$ phase is that of integration. In another study the integration phase was also found to be at higher levels (Wang \& Chen, 2008). However, it is argued that the reason for it, is the "defining rules of online discussions" and the support of instructor.

The frequency of the final CP phase, namely resolution, is found to be lower in this study, in parallel to current body of related literature. This may be resulted from various factors. One of such factors is that the online discussion process is generally carried out within the scope of a lesson and the participants do not have a chance to practice in expressing their thoughts (Akyol \& Garrisson, 2011). The phase of resolution also requires a similar time demanding formation process. The delivery and content of the course may also be a constraint for this phase. The process of courses and therefore, that of online discussion may not be enough to reach a specific outcome (Biesenbach-Lucas, 2003). In addition, the course content "may not lend itself well to advanced inquiry (e.g., an introductory course)" (Garrison et al., 2001). Thus, the occurrence of the phases integration and resolution is not so easy during the course process which is very short and focuses on a specific topic (Swan, Garrison, \& Richardson, 2009), but in order to avoid such undesired conditions online discussions may employ the boards which may produce an effective way to learn (Olesova, Slavin, \& Lim, 2016). Summarizing the first research question; there are some inconsistencies in the distribution of $\mathrm{CP}$ phases, and exploration is 
dominant phase among the other phases. These may be due in part to other factors as follows: discussion topic choices, course type/content, design of discussion boards (structured-unstructured), duration of course/online discussions and community climate.

\section{Is there any change in the level of participation and the number of words used by the participants in relation to the weeks or to their cognitive styles?}

The ratio of participation (RP) of the participants and the number of words they used in the arguments during the seven-week course are presented in Table 4.

Table 4. Frequencies of rate of participations (RP) and word counts in online discussions

\begin{tabular}{lcccccccc}
\hline Weeks & $\begin{array}{c}\text { FD } \\
\text { participants }\end{array}$ & $\begin{array}{c}\text { FI } \\
\text { participants }\end{array}$ & $\begin{array}{c}\text { Total } \\
\text { participants }\end{array}$ & $\begin{array}{c}\text { RP- } \\
\text { total } \\
(\boldsymbol{\%})\end{array}$ & $\begin{array}{c}\text { RP-FD } \\
\text { (within } \\
\text { FDs) }\end{array}$ & $\begin{array}{c}\text { RP-FI } \\
\text { (within } \\
\text { FIs) }\end{array}$ & $\begin{array}{c}\text { FD } \\
\text { word } \\
\text { count }\end{array}$ & $\begin{array}{c}\text { FI } \\
\text { word } \\
\text { count }\end{array}$ \\
\hline $\mathbf{1}$ & 13 & 16 & 29 & 50,8 & 44,8 & 57,1 & 2234 & 2771 \\
$\mathbf{2}$ & 27 & 27 & 54 & 94,7 & 93,1 & 96,4 & 2666 & 2343 \\
$\mathbf{3}$ & 7 & 7 & 14 & 24,5 & 24,1 & 25 & 780 & 754 \\
$\mathbf{4}$ & 13 & 16 & 29 & 50,8 & 44,8 & 57,1 & 1007 & 1485 \\
$\mathbf{5}$ & 9 & 12 & 21 & 36,8 & 31 & 42,9 & 1112 & 1587 \\
$\mathbf{6}$ & 13 & 11 & 24 & 42,1 & 44,8 & 39,2 & 421 & 312 \\
$\mathbf{7}$ & 23 & 23 & 46 & 80,7 & 79,3 & 82,2 & 2151 & 2226 \\
\hline
\end{tabular}

The results of the non-parametric Kruskal Wallis test indicate that the word count ( $\chi^{2}$ (2) $=8,000, \mathrm{p}<.05)$ and the RP $\left(\chi^{2}(2)=6,289, \mathrm{p}<.05\right)$ significantly vary per week. According to post hoc pairwise comparisons, one significant pairwise comparison was found in "word count" variable, that is, between the weeks 1-2 and the weeks 3-5. Another significant pairwise comparison was found in "participation" variable similarly between the weeks 1-2 and the weeks 3-5. The means for the weeks 1-2 in regard to these two variables are much higher than those for the weeks 3-5. Therefore, both participation and word count during the first two weeks are significantly higher than those in the weeks 3 5 .

The participation of the FI and FD groups in online discussions is also found to vary between the weeks $1-2$ and the weeks $3-5, \chi^{2}(2)=8,000, p<.05$. Within the groups (FD and FI style participants) the rate of participation (RP) also varies. However, this variation may not be related to their cognitive style considering the former findings in this study. It is thought that it may be a result of the questions used in online discussions.

The results of the nonparametric Mann Whitney $\mathrm{U}$ test indicate that neither the RP nor word counts significantly vary based on the cognitive style of the participants $(\mathrm{p}<.05)$. However, it should be added that the participants with different cognitive styles contribute to online discussions with a fairly similar word count in total ( $\overline{\mathrm{x}} \mathrm{FD}=709, \overline{\mathrm{x}} \mathrm{FI}=718$ ). This indicated that the learners in the FD group produced longer messages than those in the FI group.

\section{Discussion:}

In the initial process of the online learning processes, it is a well-known fact that high participation is observed in the first weeks and decrease in participation occurs in the following weeks or learners drop-out completely (Lee \& Choi, 2011; Park \& Choi, 2009). This situation may be similar in online discussion processes. The tendency of individuals with different cognitive styles to participate in online discussions and the generation of online arguments are not much discussed in the literature. The 
characteristics of the FI and FD individuals reported in the related studies suggest that the FI individual may have little tendency in interacting with others in online environments (Sezgin, 2013). On the other hand, these individuals are expected to participate in discussions using shorter and brief arguments. In this regard the findings of the study are not consistent with the previous findings. More specifically, it is found in the present study that there is no significant difference between the FD and FI individuals in terms of participation and word counts. It can be said that the FI individuals may be more targetoriented, solution-oriented and more sensitive to recognize the whole in an online environment aimed at providing a solution to a problem. In this study, it is found that the FI participants are more active and tend to focus on problem solving while dealing with new discussion topics related to their fields of expertise.

\section{Is there a pattern of cognitive style groups' cognitive presence from Week 1 to Week 7 of the course?}

In regard to the cognitive phases of the individuals with different cognitive styles (i.e., FI \& FD) it is found that in all four phases they had similar rates indicating that the exploration phase is the most frequent $\mathrm{CP}$ component. Bearing in mind that the FD and FI individuals constitute homogenous groups in this study, the FD individuals produced much more messages in the exploration phase in contrast to the FI individuals $(\mathrm{FD}=56,7 \% ; \mathrm{FI}=43,3 \%)$. It is also found that the difference between the groups is smaller in the phases of triggering event $(\mathrm{FD}=52,7 \% ; \mathrm{FI}=47,3 \%)$ and integration $(\mathrm{FD}=55,8 \%$; $\mathrm{FI}=44,2 \%$ ), but the number of arguments is still much higher for the FD group. At the phase of resolution, the FI individuals produced much more phases of the cognitive presence $(66,6 \%)$ than the FD individuals $(33,3 \%)$. However, the FD individuals produced much more arguments in contrast to the FI individuals (55\%).

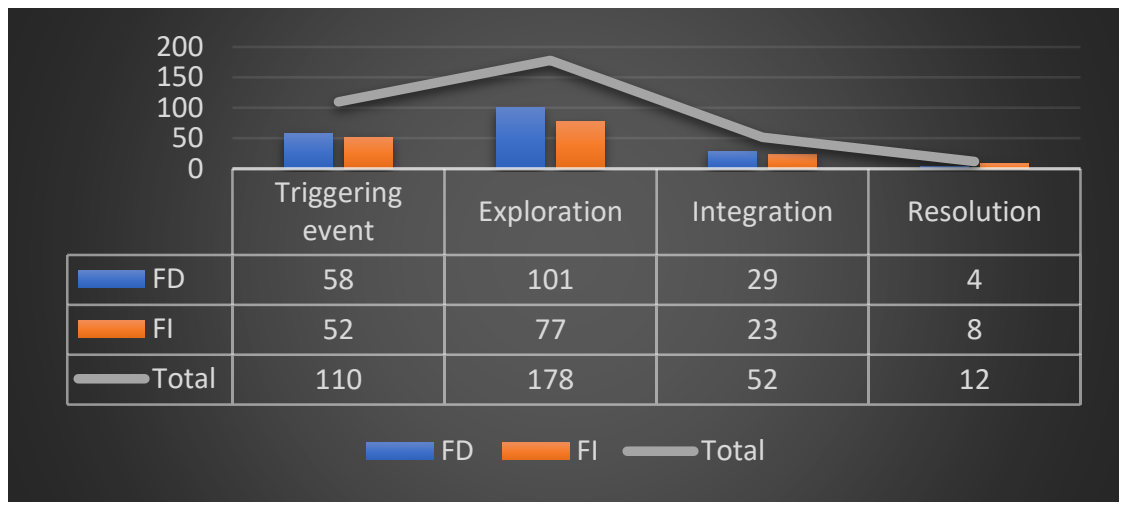

Figure 2. Number of codes in different cognitive presence phases according to cognitive style

While these numbers show variation, they do not represent statistical differences. Accordingly, the results of the nonparametric Mann Whitney U test clearly indicate that the phases of the cognitive presence do not significantly vary in relation to the cognitive style of the participants $(\mathrm{p}<.05)$. 

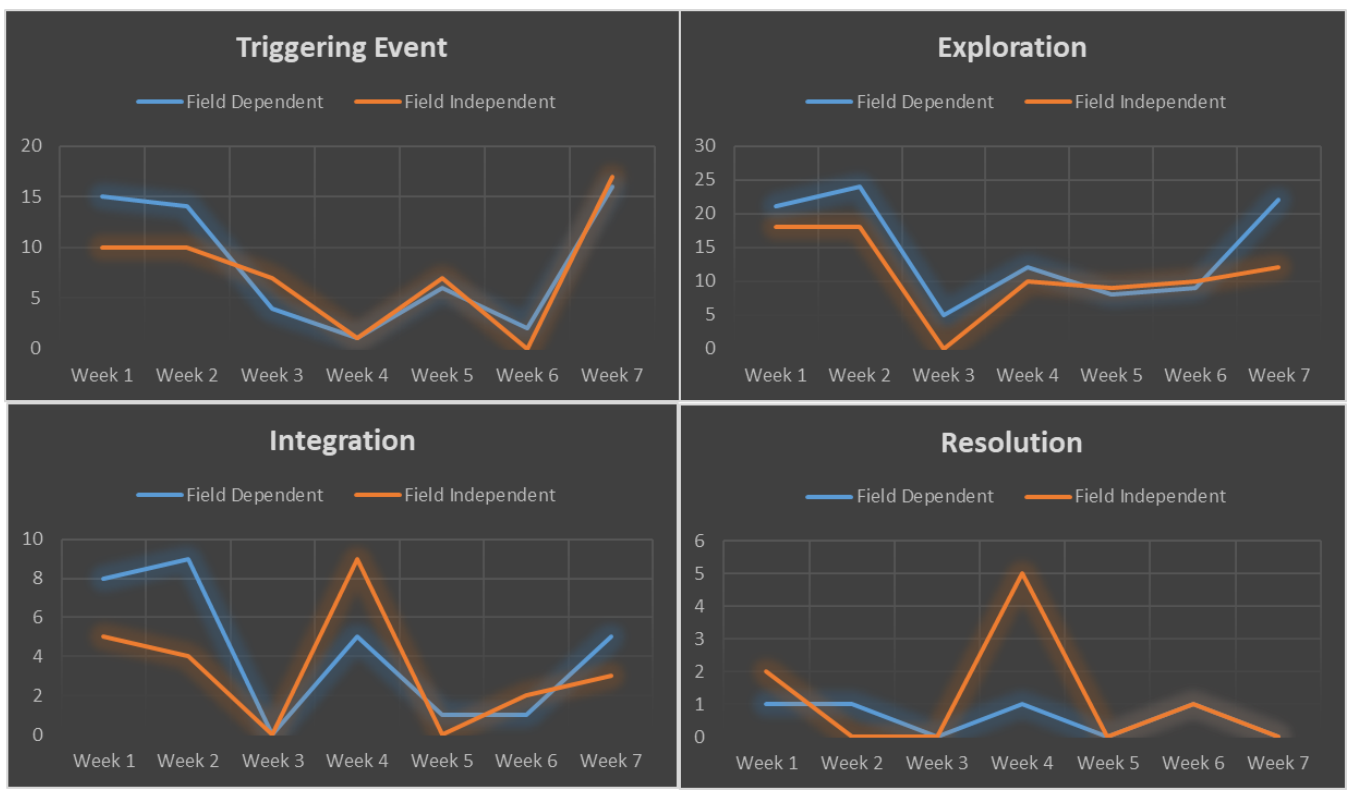

Figure 3. The coding results for categories of cognitive presence over the seven weeks

Figure 3 shows the changes in the phase of cognitive presence of the participants with different cognitive styles phase by phase during the seven-week course. As mentioned above, the phases of triggering event and exploration had much higher frequency during the early and final weeks in contrast to other weeks. The integration phase reached the peak during the first and fourth weeks. The phase of resolution has the highest frequency in the fourth week. These increases or decreases observed can be attributed to the content and structure of the discussion questions posed by the educator during the online argument development process that the learners participate on a voluntary basis.

\section{Discussion:}

Research suggests participants may be affected from the content designs of the questions used in online discussions. It is reported that poorly designed online content such as short question-answer pairs or extremely structured discussion content does not facilitate the occurrence of cognitive presence (Darabi et al., 2011). In the study by Richardson, Sadaf, and Ertmer (2013) it is stated that learners reach higher cognitive presence with regard to the discussion topics that demand solutions to specific problems. There is another study which argues that lower levels of cognitive presence may be related to the content and expression of discussion questions (McLoughlin \& Mynard, 2009). At this point, it will be useful to examine the features of the triggers used for the asynchronous online discussion. Darabi et al. (2011) report that the scaffolded strategy increased in the resolution phase, but, on the other hand, role-play strategy may increase in the integration phase. DeNoyelles et al. (2014) and Gašević, Adesope, Joksimović, \& Kovanović (2015) state that the fact that the asynchronous discussion questions are structured by instructors is a significant feature to improve the cognitive presence of learners. They also suggested distinct types of questions to have such a design. Those question types that may improve the cognitive presence of learners include the items that ask learners to produce solutions, items involving questions, project-based items and items that may create conflicts among learners. Richardson \& Ice (2010) also argue that the resolution phase is much more frequent when case-based discussion questions are employed. In addition, the role assignment strategy also contributes to the high-level of 
cognitive presence (Gašević et al., 2015). In short, the related findings indicate that scaffolded strategy, role - play strategy, role assignment, debate, design-oriented and problem-based questioning strategies that directly ask for problem solving support the higher-level of the phases of cognitive presence.

\section{Is there a significant correlation between CP phases and CS groups?}

Table 5 presents the results of the non-parametric correlation analysis which was performed to see the relationship between the cognitive phases and the cognitive styles of the participants. As presented in Table 5, no significant correlations were found between their cognitive style and overall cognitive presence phases. Accordingly, it would be better to examine the possible correlations in a holistic way instead of the relationship between the $\mathrm{CP}$ phases and their cognitive styles.

Table 5. Spearman Rhu correlation coefficients between CS and CP phases

\begin{tabular}{lllllll}
\hline & & $\mathbf{1}$ & $\mathbf{2}$ & $\mathbf{3}$ & $\mathbf{4}$ & $\mathbf{5}$ \\
\cline { 2 - 6 } & Cognitive Style & 1 & & & & \\
2 & CP-triggering event &,- 036 & 1 & & & \\
3 & CP-exploration &,- 160 &, $573^{*}$ & 1 & & \\
4 & CP-integration &,- 143 &, 240 &, $824^{* *}$ & 1 & \\
5 & CP-resolution &, 019 &,- 358 &, 314 &, $650^{*}$ & 1 \\
**. Correlation is significant at the 0.01 level (2-tailed). & & & \\
$*$ *. Correlation is significant at the 0.05 level (2-tailed). & & &
\end{tabular}

The results of a two-tailed Spearman Rhu $(\rho)$ correlation coefficients showed some significant positive correlations between the cognitive presence phases. More specifically, it is found that the triggering event phase has a positive intermediate correlation with the exploration phase of $\mathrm{CP}(\rho=.573 ; \mathrm{p}<.05)$. There is a strong positive correlation between the exploration phase and the integration phase $(\rho=.824 ; p<.01)$. It is also found that the integration phase has an intermediate and positive correlation with the resolution phase of cognitive style $(\rho=.650 ; p<.05)$.

\section{Discussion:}

Based on the correlation coefficients found, it is safe to argue that the $\mathrm{CP}$ phases are interrelated. A similar correlation analysis was employed by Morueta et al. (2016). In their study there are lower and moderate correlations observed between the phases of the triggering event and exploration, between the phrases of exploration and integration and between the phases of integration and resolution. In the present study a strong correlation is observed between the phases of exploration and integration. Remarkable correlations are also observed for the other phases. The correlation between the phases of exploration and integration may be due to technology and education related discussion tasks concluding with the integration of views in the exploration phase. The reason for this may be that the topics discussed are adaptable to daily life and various practices. The correlation between the phases of the triggering event and exploration may be related to the fact that the discussion topic is or is not structured. In the present study mostly, unstructured tasks are employed. It can be argued that the less the subject is structured, the higher the relationship between the phases of the triggering event and the exploration (Morueta et al., 2016). The correlation between the phases of the integration and resolution is found to be slightly higher than moderate level. It can be thought that the predictive, experience and academic / technical skills of the participants are crucial since they produced arguments during the integration phase about their real-life application and 
turned them into a product. However, the applicability of the tasks presented to the participants during the seven-week period is thought to be effective at the level of this relationship. From this point of view, it provides strong evidence that the selection of online discussion topics is highly important in the formation of high cognitive presence.

\section{Conclusion}

In this study, changes in cognitive presence based on time (per weeks) and cognitive style were analysed in online discussions. Online discussions are important tools for the effectiveness of open and distance learning processes. Active participation of learners in online discussions may result in effective and permanent learning. However, the effectiveness of CP to assist higher-level sustainable learning in online environments has been reported in various studies in the literature (Garrison et al., 2001; Rourke \& Kanuka, 2009). It is clear that supporting higher-order thinking skills in online discussions can also improve the higher-level learning process and individual learning outcomes within the group. Cognitive presence is one of the significant frameworks to observe the formation and development of these higher-level learning skills. The study also dealt with individual differences. Participation in online discussions and argument development can be affected by individual differences like many educational processes. Examining the effects of individual characteristics that do not change primarily or change little over time (such as cognitive style) can be an important first step in planning adaptive learning online in accordance with the first-level clustering approach based on learning analytics.

In the studies which analysed the cognitive presence in online discussions through the content analysis, it is reported that the phase of exploration is the most frequent CP phase and that the phases of integration are resolution are less frequent $\mathrm{CP}$ phases. The findings of the study confirm it. Except for the exploration phase, both the $\mathrm{CP}$ and its phases do not vary over time. Thence, it can be stated that the participants cannot manage to transit to the phases of integration and resolution. It may be resulted from the nature of courses, the characteristics of web environment where online discussions took place and the content of discussions or the length of discussions. However, the integration and resolution phases which are called high level $\mathrm{CP}$ phases, seem to be related to the learner achievement (Chen \& Chang, 2017). At this point, it should be noted that the PI model is based on John Dewey's educational philosophy of pragmatism and the approach of the hands-on experience (Garrison et al., 2001). Accordingly, encouraging students enough for the formation of integration and resolution phases will also ensure that problems used in the process reflect the real-life situations. This can bring active and therefore effective learning. From this point of view, as in this study, it is necessary to investigate which variables change depending on which variables to create effective online learning environments.

No significant relationship was found between the cognitive style of the online discussion participants and their cognitive presence. Research suggests that the FI individuals less tend to interact with others in online discussion environments in contrast to the FD individuals. However, in the present study the FI individuals were found to have similar frequency and average in regard to the interaction like the FD individuals. Therefore, in the study a different case is found: The FI individuals are highly prone to online group interaction on the topics such as developing a solution, discussing a new topic, and designing various integration processes. 
The correlation coefficients for the $\mathrm{CP}$ phases suggest that these phases seem to be highly interrelated. More specifically, the exploration phase is connected with the integration phase, and the integration phase is related to the resolution phase. These relationships seem to be the gears of a wheel. At this point, it is clear that a healthy online discussion environment must be created in order to create high level CP. The results provided evidence that CP "does not happen automatically"; at this point online course designers or facilitators should pay special attention to designing online discussion activities to contribute to rich and effective learning experiences (Darabi et al. 2011; Ertmer et al., 2011; Richardson \& Ice 2010; Sadaf \& Oleseva, 2017).

In conclusion, in order to provide an effective learning experience in online learning, it is important to engage learners in higher-order learning activities, to support cooperative learning and to perform individualized instruction. In this respect, supporting high level cognitive presence is necessary to ensure the effective online information building process to monitor the individual differences in the environment.

\section{Limitations and educational implications}

The study has some limitations. First, this study is limited in generalizability of findings due to the small sample size and due to the fact that the participants represent only one program and university. Also measuring higher-order learning outcomes is a challenging topic. Measuring latent, complex cognitive states (Akyol \& Garrison, 2011) requires significant amount of experience. In addition, performing this measurement with one of the machine learning methods that is not affected by the subjective perspectives will increase the reliability of CP studies based on content analysis.

The study produces some findings that should be taken into consideration by online learning designers. As it is known the $\mathrm{CP}$ is a significant component for effective online learning (Garrison et al., 2001). Online instructors should structure their teaching processes and questions they ask to address high-level cognitive phases. In the study the questions used in the online discussions are mostly seminal and stimulating ones that are about the current approaches in education. It is thought that such questions gave rise to the exploration phase. In terms of learning process design, it can be suggested based on the study findings that discussion boards can be employed in online learning and the questions used in the discussions should include creative components and make it possible for the learners to involve in project-based or game-drama process.

Another topic analysed in the study is the effects of individual differences on the learner involvement in online discussion environments. The impact of unchanging individual differences, such as cognitive form, on online participation is very important for adaptive learning design processes based on future learning analytics. In the study some differences were observed albeit not statistically significant. It may be resulted from the lower number of participants and future studies may include more participants and focus on the computerized processes.

The communities of inquiry model describe the components of teaching presence (TP) and social presence (SP). In future studies, the procession of the CP, TP, and SP may be analysed in relation to individual differences and cognitive styles. Such studies will contribute to make the artificial intelligence agents which imitate human cognition much more consistent with learning situations. 


\section{References}

Akyol, Z., \& Garrison, D. R. (2011). Understanding cognitive presence in an online and blended community of inquiry: Assessing outcomes and processes for deep approaches to learning. British Journal of Educational Technology, 42(2), 233250.

Arbaugh, J. B., Bangert, A., \& Cleveland-Innes, M. (2010). Subject matter effects and the community of inquiry (CoI) framework: An exploratory study. The internet and higher education, 13(1-2), 37-44.

Biesenbach-Lucas, S. (2003). Asynchronous discussion groups in teacher training classes: Perceptions of native and non-native students. Journal of Asynchronous Learning Networks, 7(3), 24-46.

Chang, B., Chen, S. Y., \& Jhan, S. N. (2015). The influences of an interactive groupbased videogame: cognitive styles vs. prior ability. Computers \& Education, 88 , 399-407.

Chen, H. L., \& Chang, C. Y. (2017). Integrating the SOP 2 Model into the Flipped Classroom to Foster Cognitive Presence and Learning Achievements. Journal of Educational Technology \& Society, 20(1).

Darabi, A., Arrastia, M. C., Nelson, D. W., Cornille, T., \& Liang, X. (2011). Cognitive presence in asynchronous online learning: A comparison of four discussion strategies. Journal of Computer Assisted Learning, 27(3), 216-227.

Davis, J. K. (1991). Educational implications of field dependence-independence. In S. Wapner \& J. Demick (Eds.), Field dependence-independence: Cognitive styles across the lifespan (pp. 149-175). Hillsdale, NJ: Lawrence Erlbaum Associates.

DeNoyelles, A., Zydney, J. M., \& Chen, B. (2014). Strategies for creating a community of inquiry through online asynchronous discussions. Journal of online learning and teaching, 10(1), 153-165.

Du, H. S., \& Wagner, C. (2007). Learning with weblogs: Enhancing cognitive and social knowledge construction. IEEE Transactions on professional communication, 50(1), 1-16.

Ertmer, P. A., Sadaf, A., \& Ertmer, D. J. (2011). Student-content interactions in online courses: The role of question prompts in facilitating higher-level engagement with course content. Journal of Computing in Higher Education, 23(2-3), 157.

Flavell, J. H. (1979). Metacognition and cognitive monitoring: A new area of cognitivedevelopmental inquiry. American psychologist, 34(10), 906.

Fraenkel, J. R., Wallen, N. E., \& Hyun, H. H. (2012). How to design and evaluate research in education (Vol. 8). New York: McGraw-Hill.

Garrison, D.R., \& Anderson, T. (2003). E-learning in 21st century: A framework for research and practice. London: Routledge Falmer.

Garrison, D. R., Anderson, T., \& Archer, W. (1999). Critical inquiry in a text-based environment: Computer conferencing in higher education. The internet and higher education, 2(2-3), 87-105.

Garrison, D. R., Anderson, T., \& Archer, W. (2001). Critical thinking, cognitive presence, and computer conferencing in distance education. American Journal of distance education, 15(1), 7-23.

Garrison, D.R., \& Akyol, Z. (2015). Thinking collaboratively in educational environments: Shared metacognition and co-regulation in communities of inquiry. In J. Lock, P. Redmond, \& P.A. Danaher (Eds.), Educational developments, practices, and effectiveness: Global perspectives and contexts (pp. 39-52). New York, NY: Palgrave Macmillan. 
Garrison, D. R., \& Arbaugh, J. B. (2007). Researching the community of inquiry framework: Review, issues, and future directions. The Internet and higher education, 10(3), 157-172.

Garrison, D. R., \& Cleveland-Innes, M. (2005). Facilitating cognitive presence in online learning: Interaction is not enough. The American journal of distance education, 19(3), 133-148.

Gašević, D., Adesope, O., Joksimović, S., \& Kovanović, V. (2015). Externally-facilitated regulation scaffolding and role assignment to develop cognitive presence in asynchronous online discussions. The internet and higher education, 24, 53-65.

Kanuka, H., Rourke, L., \& Laflamme, E. (2007). The influence of instructional methods on the quality of online discussion. British Journal of Educational Technology, 38(2), 260-271.

Koh, J. H. L., Herring, S. C., \& Hew, K. F. (2010). Project-based learning and student knowledge construction during asynchronous online discussion. The Internet and Higher Education, 13(4), 284-291.

Kovanović, V., Gašević, D., Joksimović, S., Hatala, M., \& Adesope, O. (2015). Analytics of communities of inquiry: Effects of learning technology use on cognitive presence in asynchronous online discussions. The Internet and Higher Education, 27, 74-89.

Kovanović, V., Joksimović, S., Waters, Z., Gašević, D., Kitto, K., Hatala, M., \& Siemens, G. (2016). Towards automated content analysis of discussion transcripts: A cognitive presence case. In Proceedings of the sixth international conference on learning analytics \& knowledge (pp. 15-24).

Lee, Y., \& Choi, J. (2011). A review of online course dropout research: Implications for practice and future research. Educational Technology Research and Development, 59(5), 593-618.

Lee, J-M. \& Lee, Y. (2006). Personality types and learners' interaction in web-based threaded discussion. Quarterly Review of Distance Education 7(1): 83-94

McLoughlin, D., \& Mynard, J. (2009). An analysis of higher-order thinking in online discussions. Innovations in Education and Teaching International, 46, 147-160.

Messick, S. (1984). The nature of cognitive styles: Problems and promises in educational research. Educational Psychologist, 19 (2), 59-74

Moore, J. L., \& Marra, R. M. (2005). A comparative analysis of online discussion participation protocols. Journal of Research on Technology in Education, 38(2), 191-212.

Morueta, R. T., López, P. M., Gómez, Á. H., \& Harris, V. W. (2016). Exploring social and cognitive presences in communities of inquiry to perform higher cognitive tasks. The Internet and Higher Education, 31, 122-131.

Mutlu, M., \& Temiz, B. K. (2013). Science process skills of students having field dependent and field independent cognitive styles. Educational Research and Reviews, 8(11), 766-776.

Olesova, L., Slavin, M., \& Lim, J. (2016). Exploring the Effect of Scripted Roles on Cognitive Presence in Asynchronous Online Discussions. Online Learning, 20(4), 34-53.

Park, J. H., \& Choi, H. J. (2009). Factors influencing adult learners' decision to drop out or persist in online learning. Journal of Educational Technology \& Society, 12(4), 207-217.

Richardson, J. C., \& Ice, P. (2010). Investigation students' level of thinking across instructional strategies in online discussions. Internet and Higher Education, 13, $52-59$. 
Richardson, J. A., \& Turner, T. E. (2000). Field dependence revisited I: Intelligence. Educational psychology, 20(3), 255-270.

Richardson, J. C., Sadaf, A., \& Ertmer, P. A. (2013). Relationship between types of question prompts and critical thinking in online discussions. In Educational communities of inquiry: Theoretical framework, research and practice (pp. 197222). IGI Global.

Riding, R., \& Cheema, I. (1991). Cognitive styles-an overview and integration. Educational psychology, 11(3-4), 193-215.

Rourke, L., \& H. Kanuka. (2009). Learning in communities of inquiry: A review of the literature. Journal of Distance Education 23 (1):19-48.

Sadaf, A., \& Olesova, L. (2017). Enhancing cognitive presence in online case discussions with questions based on the practical inquiry model. American Journal of Distance Education, 31(1), 56-69.

Saracho, O. N. (1997). Teachers' and students' cognitive styles in early childhood education. Westport, CT: Greenwood Publishing Group, Inc.

Schrire, S. (2004). Interaction and cognition in asynchronous computer conferencing. Instructional Science, 32, 6, 475-502.

Schrire, S. (2006). Knowledge building in asynchronous discussion groups: going beyond quantitative analysis. Computers \& Education, 46, 1, 49-70.

Sezgin, S. (2013). Effects of cognitive style to learner behaviours in online communities of practise (Unpublished master's thesis). Anadolu University, Eskisehir.

Shea, P. (2006). A study of students' sense of learning community in online environments. Journal of Asynchronous Learning Networks, 10(1), 35-44.

Shea, P., Hayes, S., Smith, S. U., Vickers, J., Bidjerano, T., Pickett, A., ... \& Jian, S. (2012). Learning presence: Additional research on a new conceptual element within the Community of Inquiry (CoI) framework. The Internet and Higher Education, 15(2), 89-95.

Sternberg, R. J., \& Zhang, L. F. (2005). Styles of thinking as a basis of differentiated instruction. Theory into practice, 44(3), 245-253.

Swan, K., Garrison, D. R., \& Richardson, J. C. (2009). A constructivist approach to online learning: The community of inquiry framework. In Information technology and constructivism in higher education: Progressive learning frameworks (pp. 4357). IGI global.

Wang, Y. M., \& Chen, V. D. T. (2008). Essential Elements in Designing Online Discussions to Promote Cognitive Presence--A Practical Experience. Journal of Asynchronous Learning Networks, 12, 157-177.

Witkin, H.A., Oltman, P.K., Raskin, E., Karp, S.A. (1971). Group Embedded Figures Test. Technical Report. Consulting Psychologists, Palo Alto CA, USA.

Witkin, H. A., Moore, C. A., Goodenough, D. R., \& Cox, P. W. (1977). Field-dependent and field-independent cognitive styles and their educational implications. Review of educational research, 47(1), 1-64.

Zimmerman, B. J. (2002). Becoming a self-regulated learner: An overview. Theory into practice, 41(2), 64-70. 